\title{
Identification of Soybean Varieties with High $\alpha$-Tocopherol Content
}

\author{
Aya Ujiie*1), Tetsuya Yamada1), Kenshiro Fujimoto(o), Yasushi Endo ${ }^{2)}$ and Keisuke Kitamura ${ }^{1)}$ \\ 1) Laboratory of Plant Genetics and Evolution, Graduate School of Agriculture, Hokkaido University, Kita, Sapporo, Hokkaido 060- \\ 8589, Japan \\ 2) Laboratory of Food and Biomolecular Science, Graduate School of Agricultural Science, Tohoku University, Aoba, Sendai, Miyagi \\ 981-8555, Japan
}

$\alpha$-Tocopherol (Toc) is the tocopherol isoform with the highest vitamin E activity. Since soybean seeds contain a low percentage of $\alpha$-Toc, increasing the $\alpha$-Toc content to improve vitamin $\mathrm{E}$ activity is a breeding objective. Little is known about the genetic variability of the tocopherol content and composition in soybeans. In the present study, we analyzed the tocopherol composition of 1,109 germplasm accessions of cultivated and wild soybean by high performance liquid chromatography (HPLC) and identified three varieties, Dobrogeance, Dobruoza 14 Pancevo and Keszthelyi Aproszemu Sarga with a high $\alpha$-Toc content. Dobrogeance showed a similar Toc composition to that of Dobruoza 14 Pancevo with the $\alpha$-Toc content being four to seven times higher than that of standard varieties and almost the same as that of total Toc. Keszthelyi Aproszemu Sarga showed a markedly increased content of $\alpha$-Toc, but a significantly lower total Toc content.

Key Words: soybean, wild soybean, tocopherol (vitamin E), genetic variability.

\section{Introduction}

Tocopherols are lipophilic antioxidants that protect lipids from peroxidation. They are known as vitamin $\mathrm{E}$ and play many important roles in human nutrition, for example, they prevent cardiovascular diseases and cancer, and enhance the immune function. They consist of a polar chromanol head group and a hydrophobic phytil tail. Four different tocopherols, $\alpha$-, $\beta$-, $\gamma$ - and $\delta$-tocopherols occur in nature and they differ from one another based on the number and position of methyl groups on the chromanol head group. Among the four tocopherols, $\alpha$-Toc displays the highest biological activity since it harbors the most potent form of vitamin $\mathrm{E}$, while in the case of $\beta-, \gamma$ - and $\delta$-Toc, the vitamin E activity is 40,10 and $1-2 \%$, respectively, of that of $\alpha$ Toc. It is considered that the $\alpha$-tocopherol transfer protein $(\alpha$-TTP) specifically binds to the fully methylated form of tocopherol, $\alpha$-Toc, in the human body and enhances its transfer into the liver (Mino and Fukuzawa 1996, Arai 1997, Bramley et al. 2000).

Tocopherol composition is different among plant organs. Among the tocopherols, $\alpha$-Toc is the most predominant form in photosynthetic tissues such as leaves and stems and among the tocopherols present in these tissues, $\alpha$-Toc accounts for about $-90 \%$. On the other hand, in seeds, oil

Communicated by Y. Takahata

Received December 1, 2004. Accepted February 17, 2005.

*Corresponding author (e-mail: uji-aya@res.agr.hokudai.ac.jp) crops such as soybean and rape generally contain a low proportion of $\alpha$-Toc, although some crops such as sunflower and safflower contain a high proportion of $\alpha$-Toc $(70-80 \%)$ in seeds (Kajimoto and Hasebe 1982, Munne-Bosch and Alegre 2002). Since the vitamin E activity of corn and soybean oil is low from a nutritional point of view, increasing the $\alpha$-Toc content and enhancing the vitamin E activity in oil crops are breeding objectives. In maize, quantitative trait loci that determine the content of individual tocopherols and total tocopherol have been identified (Rocheford et al. 2002, Wong et al. 2003). Recently, using transgenic technologies, coexpression of a gene identified in Arabidopsis that encodes the tocopherol biosynthetic enzyme 2-methyl-6phytilbenzoquinol methyltransferase with a $\gamma$-tocopherol methyltransferase gene has resulted in an increase of the $\alpha$ Toc content in soybean seeds from $10 \%$ to $>95 \%$ (Van Eenennaam et al. 2003). However, $\gamma$-Toc plays other important nutritional and functional roles. It shows a moderate antioxidant activity and appears to be a better food additive as antioxidants than $\alpha$-Toc. Recent investigations have revealed that its derivatives promote the excretion of sodium in urine, preventing renal failure and swelling, and this function is more effective when $\alpha$ - and $\gamma$-Toc are taken at the same time (Christein et al. 1997). Therefore, manipulation of the $\alpha$ and $\gamma$-Toc contents may be a more suitable breeding strategy for improving the nutrition and function of the tocopherols than increasing the content of only one type of tocopherol.

Although soybean is one of the most important oil crops, the genetic variability of the tocopherol content and 
composition is poorly documented. In the present study, we analyzed the tocopherol composition of more than one thousand cultivated and wild soybean accessions from the germplasm collection and we identified novel soybean varieties with high $\alpha$-Toc contents.

\section{Materials and Methods}

\section{Seed materials}

Nine hundred and nine soybean (Glycine $\max (\mathrm{L}$. Merr.) and 200 wild soybean (Glycine soja Sieb. and Zucc.) accessions were evaluated. The germplasm was obtained from the gene bank of the National Institute of Agrobiological Sciences in Tsukuba, Japan.

\section{Methods for screening the tocopherol composition}

Based on standard vitamin E analytical methods (Okabe and Nakamura 1985), a simple and reliable analytical procedure was used for screening the tocopherol composition in seeds. Fifty mg of ground seeds were weighed in 10 $\mathrm{ml} \mathrm{screw-capped} \mathrm{test} \mathrm{tubes} \mathrm{and} \mathrm{supersonicated} \mathrm{in} 1 \mathrm{ml}$ of $80 \%$ aqueous ethanol for $15 \mathrm{~min}$ at room temperature. Two $\mathrm{ml}$ of hexane saturated with pyrogallol was added and allowed to stand for $30 \mathrm{~min}$ at room temperature $\left(25^{\circ} \mathrm{C}\right)$. After centrifugation, $20 \mu \mathrm{l}$ of the hexane layer (upper phase) was subjected to HPLC (Hitachi LaChrom Elite, Hitachi HighTechnologies Corp., Japan) on Inertsil ODS-3 reverse phase column $(3.0 \times 250 \mathrm{~mm}, \mathrm{GL}$ Sciences, Japan $)$ at $40^{\circ} \mathrm{C}$ with a $0.5 \mathrm{ml} / \mathrm{min}$ flow rate using $\mathrm{CH}_{3} \mathrm{CN} / \mathrm{CH}_{3} \mathrm{OH}(75: 25 \mathrm{v} / \mathrm{v})$ for $25 \mathrm{~min}$. Tocopherols were detected by UV at $295 \mathrm{~nm}$.

\section{Quantification of individual tocopherols and total tocoph-} erol

As an internal standard, tocol (Tama Biochemical Co., Ltd., Japan) was mixed with an extraction buffer ( $80 \%$ aqueous ethanol) for the quantification of individual tocopherols and total tocopherol. Fifty mg of ground seeds were weighed in $10 \mathrm{ml}$ screw-capped test tubes and supersonicated in $1 \mathrm{ml}$ of $80 \%$ aqueous ethanol containing $3-5 \mu \mathrm{g}$ tocol for $15 \mathrm{~min}$ at room temperature $\left(25^{\circ} \mathrm{C}\right)$. Then after, the same procedure was used in the screening method. Individual tocopherols were quantified based on the ratio of the area of each isoform peak compared to the internal standard. Total tocopherol content was calculated by summing up the content of the individual tocopherols.

\section{Results and Discussion}

\section{Identification of soybean varieties with increased contents of $\alpha$-tocopherol}

We analyzed the tocopherol composition of cultivated and wild soybean accessions by HPLC. Three major peaks which corresponded to $\delta$-, $\gamma$ - and $\alpha$-Toc were obtained for all the accessions. In the separation procedure used in the present investigation, $\beta$ - and $\gamma$-Toc could not be separated, and since the $\beta$-Toc content was very low in soybean seeds, the $\beta$-Toc peak was not considered. Figure 1-A and -B show that the HPLC chromatograms for cv. Ichihime and cv. Toyokomachi, respectively, gave large peaks of $\delta$ - and $\gamma$-Toc and a small peak for $\alpha$-Toc. Standard tocopherol concentrations of $\delta$-, $\gamma$ - and $\alpha$-Toc in mature seeds of common soybean varieties are about $30 \%, 65 \%$ and $5 \%$, respectively (Kajimoto and Hasabe 1982). Most of the accessions analyzed showed similar chromatograms to those observed in Figure 1-A and -B. However, three varieties, Dobrogeance, Dobruoza 14 Pancevo and Keszthelyi Aproszemu Sarga gave different chromatograms and displayed larger peak areas for $\alpha$-Toc. All the varieties with increased $\alpha$-Toc contents identified so far had consisted of cultivated soybean accessions.

The varieties with high $\alpha$-Toc contents (referred to as "high $\alpha$-Toc varieties") can be classified into two types based on the elution profile of the individual tocopherols in the HPLC chromatograms: (1) that of vars. Dobrogeance and Dobruoza 14 Pancevo with a smaller peak of $\delta$-Toc, similar peak area of $\gamma$-Toc and larger peak area of $\alpha$-Toc compared to the typical accessions analyzed (Fig. 1-C); and (2) that of


(D)

Fig. 1. HPLC chromatograms of tocopherols in soybean seeds for (A) cv. Ichihime, (B) cv. Toyokomachi, (C) var. Dobrogeance and (D) var. Keszthelyi Aproszemu Sarga. Peaks 1, 2 and 3 correspond to $\delta$-, $\gamma$ - and $\alpha$-tocopherol, respectively. 
Table 1. Tocopherol composition of soybean varieties

\begin{tabular}{|c|c|c|c|c|c|c|}
\hline \multirow{2}{*}{ Accessions } & \multicolumn{4}{|c|}{ Tocopherols $(\mathrm{mg} / 100 \mathrm{~g} \text { meal) })^{1)}$} & \multirow{2}{*}{$\begin{array}{c}\text { Genebank stock } \\
\text { number }\end{array}$} & \multirow{2}{*}{ Origin } \\
\hline & $\delta$ & $\gamma$ & $\alpha$ & Total & & \\
\hline Dobrogeance & $1.59 \pm 0.26$ & $5.72 \pm 0.55$ & $3.71 \pm 0.29$ & $11.02 \pm 1.05$ & 00034330 & Romania \\
\hline Dobrudza $14 \mathrm{P}$. & $1.53 \pm 0.24$ & $6.60 \pm 0.16$ & $3.26 \pm 0.12$ & $11.39 \pm 0.46$ & 00034283 & Yugoslavia \\
\hline Keszthelyi A.S. & $1.09 \pm 0.10$ & $2.65 \pm 0.08$ & $4.26 \pm 0.32$ & $8.00 \pm 0.30$ & 00034187 & Hungary \\
\hline Toyokomachi & $5.35 \pm 0.16$ & $5.11 \pm 0.17$ & $0.49 \pm 0.42$ & $10.95 \pm 0.73$ & 00058196 & Japan \\
\hline Ichihime & $4.90 \pm 0.08$ & $6.93 \pm 0.11$ & $0.96 \pm 0.15$ & $12.79 \pm 0.25$ & - & Japan \\
\hline
\end{tabular}

1) Values are mean of three replicates $\pm \mathrm{SD}$.

var. Keszthelyi Aproszemu Sarga with smaller peak areas of $\delta$ - and $\gamma$-Toc and a significantly larger peak of $\alpha$-Toc compared to the typical accessions analyzed (Fig. 1-D).

\section{Quantitative analysis of tocopherols of the high $\alpha-T o c$ vari- eties}

Quantitative analysis of the tocopherol concentrations in seeds from the three high $\alpha$-Toc varieties using tocol as the internal standard is summarized in Table 1. Seeds of var. Dobrogeance and var. Dobruoza 14 Pancevo were grown at the National Agricultural Research Center for Tohoku Region, Akita in 2001. Seeds of var. Keszthelyi Aproszemu Sarga were grown at the National Shikoku Agricultural Experiment Station, Kagawa in 1998. Seeds of cv. Toyokomachi and cv. Ichihime used to represent standard cultivars grown in Japan were grown at the Hokkaido University Agricultural Farm in 2003.

Three high $\alpha$-Toc varieties, var. Dobrogeance, var. Dobruoza 14 Pancevo and var. Keszthelyi Aproszemu Sarga, respectively, showed higher $\alpha$-Toc contents than those of cv. Toyokomachi and cv. Ichihime (Table 1). In the present study, the high $\alpha$-Toc trait of these varieties was considered to be stable among different years. However, although the total tocopherol content of var. Dobrogeance and var. Dobruoza 14 Pancevo was similar to that of cv. Toyokomachi and cv. Ichihime, the content of var. Keszthelyi Aproszemu Sarga was significantly lower.

Further studies are under way to analyze the genetic control of the high $\alpha$-Toc trait in the three high $\alpha$-Toc varieties identified. In addition, it will be necessary to determine the extent to which the tocopherol composition is influenced by environmental conditions such as growth temperature, because it was reported that the tocopherol composition and/ or contents significantly influenced by the temperature during the seed ripening time (Almonor et al. 1998, Dolde et al. 1999, Britz and Kremer 2002).

\section{Literature Cited}

Almonor,G.O., G.P.Fenner and R.F.Wilson (1998) Temperature ef- fects on tocopherol composition in soybeans with genetically improved soy oil quality. J. Am. Oil Chem. Soc. 75: 591-596.

Arai,H. (1997) Structure and function of $\alpha$-tocopherol transfer protein - Major determinant of plasma vitamin E level—. Vitamins 71: 17-28 (in Japanese with English summary).

Bramley, P.M., I.Elmadfa, A.Kafatos, F.J.Kelly, Y.Manios, H.E. Roxborough, W. Schuch, P.J.A. Sheehy and K.-H. Wagner (2000) Vitamin E. J. Sci. Food Agric. 80: 913-938.

Britz, S.J. and D.F.Kremer (2002) Warm temperature or drought during seed maturation increases free $\alpha$-tocopherol in seeds of soybean (Glycine max [L.] Merr.). J. Agric. Food Chem. 50: 6058-6063.

Christein, S., A.A. Woodall, M.K. Shigenaga, P.T. Southwell-Keely, M.W.Duncan and B.N.Ames (1997) $\gamma$-tocopherol traps mutagenic electrophiles such as NOx and complements $\alpha$-tocopherol: Physiological implications. Proc. Natl. Acad. Sci. USA 94: 3217-3222.

Dolde, D., C.Vlahakis and J.Hazebroek (1999) Tocopherols in breeding lines and effects of planting location, fatty acid composition, and temperature during development. J. Am. Oil Chem. Soc. 76: 349-355.

Kajimoto,G. and A.Hasebe (1982) Compositions of fatty acids and tocopherols in various parts of some vegetable oilseed. J. Jpn. Soc. Food. Nutr. 35: 291-296 (in Japanese with English summary).

Mino,M. and K.Fukuzawa (1996) Vitamin E. In "Vitamin no jiten" The Vitamin Society of Japan, Kyoto (ed.), Asakura-Shoten, Tokyo, Japan. p. 91-122 (in Japanese).

Munne-Bosch,S. and L.Alegre (2002) The function of tocopherols and tocotrienols in plants. Crit. Rev. Plant Sci. 21:31-57.

Okabe, K. and T.Nakamura (1985) Vitamin E no teiryohou. In "Vitamin E-kiso to rinshou-" Igarashi,O. (ed.), Ishiyaku Pub., Inc., Tokyo, Japan. p. 14-21 (in Japanese).

Rocheford, T.R., J.C.Wong, C.O.Egesel and R.J.Lambert (2002) Enhancement of vitamin E levels in corn. J. Am. Coll. Nutr. 21: 191S-198S.

Van Eenennaam, A.L., K. Lincoln, T.P.Durrett, H.E. Valentin, C.K. Shewmaker, G.M.Thorne, J.Jiang, S.R.Baszis, C.K.Levering, E.D.Aasen, M.Hao, J.C.Stein, S.R.Norris and R.L.Last (2003) Engineering vitamin E content: From Arabidopsis mutant to soy oil. Plant Cell 15: 3007-3019.

Wong,J.C., R.J.Lambert, Y.Tadmor and T.R.Rocheford (2003) QTL associated with accumulation of tocopherols in maize. Crop Sci. 43: 2257-2266. 